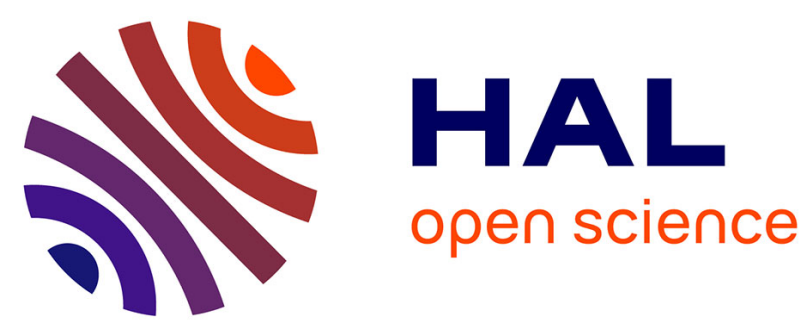

\title{
Kinetic modeling of polyurethane pyrolysis using non-isothermal thermogravimetric analysis
}

Ghassan Jomaa, Patrick Goblet, Christophe Coquelet, Morlot Vincent

\section{To cite this version:}

Ghassan Jomaa, Patrick Goblet, Christophe Coquelet, Morlot Vincent. Kinetic modeling of polyurethane pyrolysis using non-isothermal thermogravimetric analysis. Thermochimica Acta, 2015, 612, pp.10-18. 10.1016/j.tca.2015.05.009 . hal-01158620

\section{HAL Id: hal-01158620}

https://hal-mines-paristech.archives-ouvertes.fr/hal-01158620

Submitted on 12 Jan 2016

HAL is a multi-disciplinary open access archive for the deposit and dissemination of scientific research documents, whether they are published or not. The documents may come from teaching and research institutions in France or abroad, or from public or private research centers.
L'archive ouverte pluridisciplinaire HAL, est destinée au dépôt et à la diffusion de documents scientifiques de niveau recherche, publiés ou non, émanant des établissements d'enseignement et de recherche français ou étrangers, des laboratoires publics ou privés. 


\section{Accepted Manuscript}

Title: Kinetic modeling of polyurethane pyrolysis using non-isothermal thermogravimetric analysis

Author: Ghassan JOMAA Patrick GOBLET Christophe COQUELET Vincent MORLOT

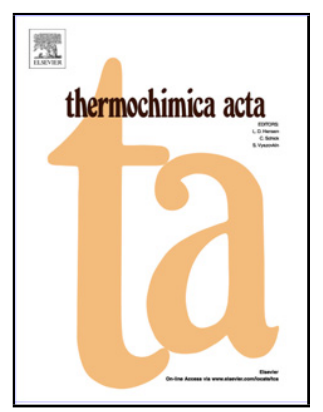

PII: S0040-6031(15)00205-1

DOI: http://dx.doi.org/doi:10.1016/j.tca.2015.05.009

Reference: TCA 77228

To appear in: Thermochimica Acta

Received date: 29-11-2014

Revised date: $11-5-2015$

Accepted date: $12-5-2015$

Please cite this article as: Ghassan JOMAA, Patrick GOBLET, Christophe COQUELET, Vincent MORLOT, Kinetic modeling of polyurethane pyrolysis using non-isothermal thermogravimetric analysis, Thermochimica Acta (2015), http://dx.doi.org/10.1016/j.tca.2015.05.009

This is a PDF file of an unedited manuscript that has been accepted for publication. As a service to our customers we are providing this early version of the manuscript. The manuscript will undergo copyediting, typesetting, and review of the resulting proof before it is published in its final form. Please note that during the production process errors may be discovered which could affect the content, and all legal disclaimers that apply to the journal pertain. 


\title{
Kinetic modeling of polyurethane pyrolysis using non-isothermal thermogravimetric analysis
}

\author{
Ghassan JOMAA $^{\mathrm{a}, \mathrm{c}}$, Patrick GOBLET ${ }^{\mathrm{a}, *}$, Christophe COQUELET $^{\mathrm{b}}$, Vincent MORLOT ${ }^{\mathrm{c}}$ \\ ${ }^{a}$ MINES ParisTech, PSL Research University, Centre de Géosciences, 35 rue Saint Honoré 77305 Fontainebleau, \\ France \\ ${ }^{b}$ Mines ParisTech, PSL Research University, CTP-Centre of Thermodynamic of Processes, 35 rue Saint Honoré 77305 \\ Fontainebleau, France \\ ${ }^{c}$ Équipe Recherche et Développement, MONTUPET S.A., 3 rue de Nogent, 60290 Laigneville, France
}

\begin{abstract}
The pyrolysis of polyurethane was studied by dynamic thermogravimetry analysis (TGA). The studied polyurethane is used as organic binder in casting process to make sand cores and molds. A semi-empirical model is presented that can be used to describe polyurethane pyrolysis occurring during TGA experiments. This model assumes that the polyurethane is pyrolysed by several parallel independent reactions. The kinetic parameters of polyurethane pyrolysis were evaluated by fitting the model to the experimental data obtained by TGA over a wide variety of heating rates. A nonlinear least-squares optimization method is employed in the fitting procedure. A hybrid objectives based simultaneously on the mass (TG) and mass loss rate (DTG) curves has been used in the least-squares method. The values of the activation energy obtained by the nonlinear fitting were then recalculated by the methods of Kissinger and Friedmand. Furthermore, the parameters obtained in the present paper were then compared with those reported in the literature.
\end{abstract}

Keywords:

kinetic parameters, polyurethane, pyrolysis, thermogravimetry, kinetic modeling

\section{Introduction}

Polyurethane is widely used in foundry industry as an organic binder to harden sand cores. The latter are inserted into a metallic mold to obtain internal shapes of casting parts. Pouring of a molten metal into the mold causes the thermal decomposition of polyurethane and gas emissions which can represent a severe problem for the quality of the casting parts. Indeed, under the effect of the thermal decomposition of the polyurethane, the pressure of the cores increases (due to the produced gas). If the local gas pressure in the sand cores exceeds the local metallostatic pressure of the solidifying liquid metal at core-casting part interface, gas bubbles can grow into the metal. Depending on whether the gas bubbles escapes through the metal or not, two possible scenarios can occur. In the first one the gas can escape through the casting part, so its effect might

*. Corresponding author

Email address: patrick.goblet@mines-paristech.fr (Patrick GOBLET ) 


\section{Experimental results}

The polyurethane binder studied in this work was prepared by the reaction of phenolic resin and polyisocyanate resin. Both resins are in a liquid form and in combination with organic solvents. A blend of an equal weight of phenolic and polyisocyanate resins were mixed to form a reaction mixture. The formation of polyurethane occurred in the presence of a gaseous amine catalyst (dimethylethanolamine). The obtained solid polyurethane was ground using a mortar and pestle. Three samples were prepared with initial masses of $16.7,16.0$ and $16.4 \mathrm{mg}$. The analyses of the samples were conducted by a Perkin-Elmer TGA 7 thermobalance. The samples were heated in nitrogen flow at different heating rates : 20,60 and $80^{\circ} \mathrm{C} \mathrm{min}^{-1}$. The mass loss and the mass loss rate curves of the polyurethane are given in figure 1 . The results shows that the average value of the residual mass of polyurethane equals around $26.75 \%$ of initial mass of the various samples. 


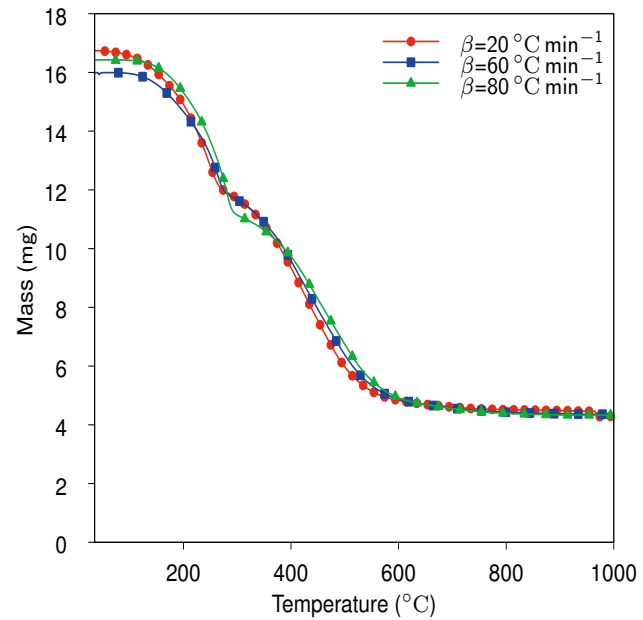

(a) TG curves

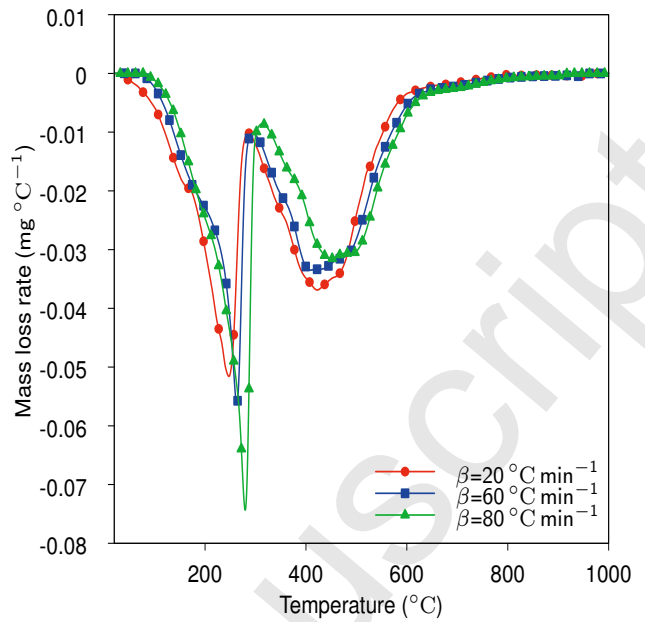

(b) DTG curves

FIGURE 1: Experimental data of polyurethane pyrolysis obtained by TGA analysis conducted in nitrogen atmosphere and at various heating rates : 20, 60 and $80^{\circ} \mathrm{C} \mathrm{min}-1$

\section{Kinetic Models of organic solid pyrolysis}

\section{Kinetic Model of polyurethane pyrolysis} account the heterogeneity of the studied solid matter.

There are abundance of published research works dealing with the modeling of the pyrolysis of solid matter using TGA. In these works, several kinetic models were employed to describe the pyrolysis of organic solids. We can mention among the used kinetic models : the single global reaction model [9-12], the parallel independent reactions model [13-17], and the distributed activation energy model [18-22]. In the single global reaction model, the pyrolysis of organic solid is described by only one reaction. This model is the simplest kinetic model that one can use. It is generally employed to describe thermal decomposition of a pure homogeneous solid. The parallel reaction model assumes that the organic solid is constituted of many solid fractions (pseudo-components) each of which is decomposed independently by one reaction. Therefore, the interaction of pyrolysis reactions of different pseudo-components is neglected. This model is essentially used to describe the pyrolysis of organic solid blends and mixtures. In the distributed activation energy model, the organic matter is assumed to be decomposed by an infinite number of parallel independent reactions. Each reaction has its own activation energy and the sum of all reactions is given by a distributed activation energy. This model is used generally to take into

In this section, the kinetic model used in our study to describe polyurethane pyrolysis will be presented. This model is based on a parallel independent reactions model. In this model, the organic solid, noted $M$, will be considered as a mixture of $n p$ pseudo-components, noted $M_{j}$. The pseudo-components are supposed to decompose independently from one another, and not to 
73 influence each other. The pyrolysis of each pseudo-component produces a gas noted $G_{j}$ and a 74 solid noted $C_{j}$. Therefore the pyrolysis of $M$ could be described by the reaction scheme R. 1 .

$$
M_{j} \longrightarrow s_{j} C_{j}+\left(1-s_{j}\right) G_{j} \quad j=1, \ldots, n p
$$

Where $s_{j}$ is the mass-based stoichiometric coefficient of pyrolysis reaction of solid pseudocomponent $M_{j} . n p$ is the number of parallel reactions. The conversion rate of each reaction $\mathrm{j}$ is given by the following equation :

$$
\frac{d \alpha_{M_{j}}}{d t}=k_{j}\left(1-\alpha_{M_{j}}\right)^{n_{j}} \quad j=1, n p
$$

Where $n_{j}$ is the order of the reaction. $\alpha_{M_{j}}$ is the conversion ratio of pyrolysable part of pseudocomponent $M_{j}$. It is defined as :

$$
\alpha_{M_{j}}=\frac{m_{M_{j}}^{0}-m_{M_{j}}}{m_{M_{j}}^{0}-m_{M_{j}}^{\infty}} \quad j=1, \ldots, n p
$$

Where $m_{M_{j}}^{0}$ is the initial mass of $M_{j} . m_{M_{j}}$ the mass of $M_{j}$ during the pyrolysis reaction. $m_{M_{j}}^{\infty}$ is the final mass of $M_{j}$ when the reaction is complete.

The kinetic coefficients $k_{j}$ are function only of temperature. $k_{j}$ are given in an Arrhenius form :

$$
k_{j}=Z_{j} \exp \left(\frac{-E a_{j}}{R T}\right) \quad j=1, n p
$$

Where $Z_{j}, E a_{j}$ and $R$ are the pre-exponential factors, activation energies, and the universal gas constant, respectively. The overall conversion rate of the solid matter $M$ is given by a linear combination of conversion rates of $M_{j}$ and, is expressed by the equation (4).

$$
\frac{d \alpha_{M}}{d t}=\sum_{j=1}^{n p} c_{j} Z_{j} \exp \left(\frac{-E a_{j}}{R T}\right)\left(1-\alpha_{M_{j}}\right)^{n_{j}}
$$

Where the coefficient $c_{j}$ represents the fraction of the overall mass loss due to the pseudocomponent $M_{j}$. The sum of these coefficients has to be equal to unity :

$$
\sum_{j=1}^{n p} c_{j}=1
$$

89

In the same way, the conversion ratio of the solid matter $\mathrm{M}$ is given by a linear combination so of conversion ratio of different pseudo-components $M_{j}$ :

$$
\alpha_{M}=\sum_{j=1}^{n p} c_{j} \alpha_{M_{j}}
$$

$\alpha_{M}$ can be calculated using TGA results by the following equation :

$$
\alpha_{M}=\frac{m_{M}^{0}-m_{M}}{m_{M}^{0}-m_{M}^{\infty}}
$$


$m_{M}^{0}, m_{M_{j}}^{\infty}$ and $m_{M_{j}}$ are the initial, final and current weights of $M$. If we consider that the TGA experiments have been carried out in non-isothermal conditions, the conversion rate of the organic matter $M$ might be written as :

$$
\frac{d \alpha_{M}}{d t}=\frac{d T}{d t} \frac{d \alpha_{M}}{d T}=\beta \frac{d \alpha_{M}}{d T}
$$

Therefore, we have :

$$
\frac{d \alpha_{M}}{d T}=\frac{1}{\beta} \sum_{j=1}^{n p} c_{j} Z_{j} \exp \left(\frac{-E a_{j}}{R T}\right)\left(1-\alpha_{M_{j}}\right)^{n_{j}}
$$

where $\beta=d T / d t$ is the heating rate of sample during the TGA experiments. If the sample is subjected to a linear temperature ramp, the temperature can be expressed by the following equation :

$$
T=\beta t+T^{0}
$$

Where $\mathrm{t}$ is time and $T^{0}$ is the initial temperature of the sample. For each reaction, there are four kinetic parameters $\left(c_{j}, Z_{j}, E a_{j}\right.$ and $\left.n_{j}\right)$.

Using the definition of ratio conversion $\alpha_{M}$ given by the equation (7), the rate conversion of $M$ can be evaluated by equation (11).

$$
\frac{d \alpha_{M}}{d T}=\frac{-1}{m_{M}^{0}-m_{M}^{\infty}} \frac{d m_{M}}{d T}
$$

If we consider also $n p$ as an unknown, the model would have $4 \times n p+1$ kinetic parameters which have to be determined by fitting kinetic model equations to experimental data obtained by TGA.

\section{Determination of kinetic parameters}

There are several methods for determining the kinetic parameters of the pyrolysis of solid materials. We may classify them as linear and nonlinear methods. It is worthy to note that this classification is based upon the mathematical analysis of the experimental results. An classification according to experimental conditions of pyrolysis analysis such as isothermal and nonisothermal may be also used [23].

\subsection{Linear Methods}

These methods consist of finding a linear relationship between the kinetic parameters using the reaction rate given by the considered kinetic model. Then using the experimental results the coefficients of the linear relation are determined by a linear regression. Those method are generally applied for a simple kinetic model in which the solid material is supposed to be decomposed in a single step. It is so described by one elementary reaction. This is the case where we have one reaction in the pyrolysis model presented above. In this case the reaction rate is given by the following equation :

$$
\frac{d \alpha_{M}}{d T}=\frac{Z}{\beta} \exp \left(\frac{-E a}{R T}\right)\left(1-\alpha_{M}\right)^{n}
$$


This expression of reaction rate is used when the reaction mechanism is characterized by a homogeneous chemical kinetic [24]. For more general case of other reaction mechanisms, the reaction rate can be expressed as shown below :

$$
\frac{d \alpha_{M}}{d T}=\frac{Z}{\beta} \exp \left(\frac{-E a}{R T}\right) f\left(\alpha_{M}\right)
$$

Where $f\left(\alpha_{M}\right)$ is the reaction function which can take many mathematical forms depending on the controlling reaction mechanism. For example, some forms of this function can be found in $[23,25-30]$.

Many linear methods have been reported in the literature [23, 30-34]. The Friedman and Kissinger Methods are presented above.

\subsubsection{Friedman Method}

This method was introduced by Friedman [35]. The linear relationship employed by this method is obtained by taking the logarithm of the equation (13) which leads to the expression (14).

$$
\ln \left(\beta \frac{d \alpha_{M}}{d T}\right)=\ln Z+\ln f\left(\alpha_{M}\right)-\frac{E a}{R T}
$$

For a given conversion degree $\alpha_{M}$, plotting $\ln \left(\beta \frac{d \alpha_{M}}{d T}\right)$ as a function of $\frac{1}{T}$ for several heating rates yields a straight line whose slope is equal to $\frac{-E a}{R}$. Therefore the activation energy of the reaction $E a$ is obtained from the slope. We note that the estimation of the activation energy by Friedman method does not require to know the reaction function $f\left(\alpha_{M}\right)$. This is why this method is considered as a free-model method. In order to estimate the pre-exponential factor $Z$ from the y-intercept of the straight line, the function $\left.f\left(\alpha_{M}\right)\right)$ must be known.

\subsubsection{Kissinger Method}

This method was firstly introduced by Kissinger [36]. It is based on the temperature of the maximum rate of conversion (temperature of peaks in DTG). Indeed, the derivative of the conversion rate is equal to zero at the peak temperature of the DTG curve. The derivative of the conversion rate is given by the equation (15).

$$
\frac{d^{2} \alpha_{M}}{d T^{2}}=\left[\frac{E a}{R T^{2}}+\frac{Z}{\beta} \exp \left(\frac{-E a}{R T}\right) \frac{d f\left(\alpha_{M}\right)}{d \alpha_{M}}\right] \frac{d \alpha_{M}}{d T}
$$

If we assume that the maximum reaction rate occurs at the peak temperature $T_{\max }$, as the derivative of the conversion rate at $T_{\max }$ is equal to zero, we obtain the following equation :

$$
\frac{E a}{R T_{\max }^{2}}-\frac{m Z}{\beta} \exp \left(\frac{-E a}{R T_{\max }}\right)=0
$$

Which may also be rearranged in the following form

$$
\frac{\beta}{T_{\max }^{2}}=\frac{m Z R}{E a} \exp \left(\frac{-E a}{R T_{\max }}\right)
$$


Where $m=-\left.\frac{d f\left(\alpha_{M}\right)}{d \alpha_{M}}\right|_{T=T_{\max }}$. Taking the logarithm of this equation leads to the linear relationship of Kissinger :

$$
\ln \left(\frac{\beta}{T_{\max }^{2}}\right)=\ln \left(\frac{m Z R}{E a}\right)-\frac{E a}{R T_{\max }}
$$

For a set of DTG curves with different heating rates $\beta$, the plot of $\ln \left(\frac{\beta}{T^{2}}\right)$ as a function of $\frac{1}{T_{m a x}}$ would lead to a straight line whose slope $\frac{-E a}{R}$ gives the activation energy. Kissinger method is also considered as model-free method. If the form of the function $f\left(\alpha_{M}\right)$ is known, the preexponential factor $Z$ constant can be further determined from the y-intercept of the obtained straight line.

\subsection{Non-linear Methods}

This type of methods is based on nonlinear least-square regression [37-42]. The kinetic parameters are calculated in this method by minimizing an objective function based on the sum of weighted square of the error between the experimental data of thermogravimetry analysis and model equations. These methods allow a direct fitting of the model equations to the experimental data without any rearrangement or approximation. Moreover, they are robust methods to estimate kinetic parameters of models with complex reaction schemes .

Depending on whether the conversion ratio or the conversion rate of the pseudo-compounds is used, the objective function may be defined in two ways. In the first one, the objective function is defined by the conversion ratio :

$$
O f^{I}(\mathbf{a})=100 \times \sqrt{\sum_{l=1}^{N_{T G A}} \sum_{i=1}^{N_{\text {exp }}^{l}} \frac{\left[\alpha_{M}^{e x p, l}\left(t_{i}\right)-\alpha_{M}^{l}\left(t_{i}, T_{i}, \mathbf{a}\right)\right]^{2}}{N_{\exp }^{l}}}
$$

$\mathbf{a}$ is the vector of the kinetic parameters to be estimated. It is defined as follows :

$$
\mathbf{a}=\left\{E a_{1}, \ldots ., E a_{n p}, Z_{1}, \ldots ., Z_{n p}, c_{1}, \ldots ., c_{n p}, n_{1}, \ldots ., n_{n p}\right\}^{\top}
$$

$N_{T G A}$ and $N_{\text {exp }}^{l}$ are the numbers of TGA experiments and of points, respectively, in a given experiment. Subscript $l$ indicates the different experiments. $\alpha_{M}^{\text {exp, } l}\left(t_{i}\right)$ and $\alpha_{M}^{l}\left(t_{i}, T_{i}, \mathbf{a}\right)$ denote the experimental and estimated conversion ratios at instant $t_{i}$ (temperature $T_{i}$ ). This form of the objective function is called the integral form. The other form of the objective function is defined based on the conversion rate equation :

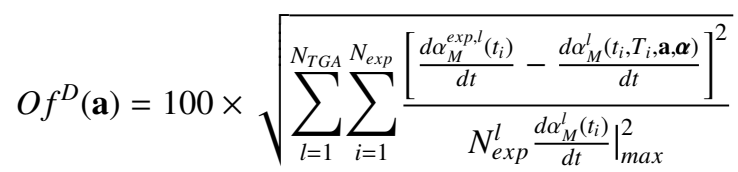

This form of the objective function is called the differential form. The division by $\left.\frac{d \alpha_{M}^{e x p l}\left(t_{i}\right)}{d t}\right|_{\max } ^{2}$ serves to normalize the conversion rate of different samples. In fact, since the TGA experiments are carried out at different heating rates, the difference between the conversion rate of different samples could be very important. Therefore, in order to consider the effect of all experiments in the objective function, the conversion rate of each sample is divided by its maximum value $[43,44]$. 
It is important to note that both forms of the objective functions have been used in the literature to determine the kinetic parameters. Studies such as the ones of [15, 40, 45] and [46] have employed the integral form. As examples of studies that have used the differential form, we mention [16, 47, 48] and [49]. The difference between the estimation of kinetic parameters by the integral and differential forms of objective function have been rarely discussed in various publications. A discussion of the difference between these two forms was conducted by [22]. According to Várhegyi et al. [22], it is somewhat difficult to determine the most appropriate form to determine the kinetic parameters. A good choice for the estimation of kinetic parameters of reactions with slow conversion rates would be the integral form. In other cases, the minimization of the differential form is the most sensible to estimate the kinetic parameters choice.

In this paper, we use a hybrid form of the objective function that simultaneously takes into account the minimization of both integral and differential forms (19) and (20). This hybrid form is given by the following function :

$$
O f=\sqrt{(1-\lambda) O f^{I^{2}}+\lambda O f^{D^{2}}}
$$

where $\lambda$ is a number varying between 0 and 1 . When $\lambda$ equals to 0 , we get the integral form of objective function. When $\lambda$ equals to 1 , the form of the objective function is the differential one. In order to determine the kinetic parameters, the minimization of the objective function (21) has been achieved using the pattern search method of Hooke-Jeeves [50, 51] method. It is an iterative method of minimization which does not require the calculation of derivatives of the objective function. This method has been used by Várhegyi et al. [49] to determine the kinetic parameters. [49] has shown that even tough this method converges slowly toward the optimal parameters, it is an efficient method.

The evaluation of the objective function requires the calculation of the conversion ratio and conversion rate of polyurethane pyrolysis. The calculation of these values was obtained by the numerical integration of the differential equations given by the equations of rate conversion of the different pseudo-components (Eq. 4). The integration is conducted by the fourth-order RungeKutta method.

\section{Results and discussion}

Figures 1 shows that the decomposition of the different samples starts at $100^{\circ} \mathrm{C}$. DTG curve illustrates clearly that the pyrolysis of polyurethane is occurring in at least two steps which correspond to the successive reactions of thermal decomposition of the polyol resins and the polyisocyanate resin. The first one takes place between 100 and $300{ }^{\circ} \mathrm{C}$. About $50 \%$ of the total decomposed mass of polyurethane is lost in the first step. The second one starts approximately at 300 and extends to $800{ }^{\circ} \mathrm{C}$. Therefore, the polyurethane decomposes in a broader range in the second step. Otherwise, in this step about $50 \%$ of total decomposed polyurethane is lost. It is important to note that the final char residue represents about $26.75 \%$ of initial mass of samples.

\subsection{Decomposition of polyurethane by two parallel independent reactions}

In order to determine the kinetic parameters of polyurethane pyrolysis, we supposed firstly that the decomposition of the polyurethane is done by two parallel independent reactions. In other words, the decomposition of polyurethane in each step will be described by one reaction. As initial values for the kinetic parameters we have taken : $1 \times 10^{5} \mathrm{~kJ} \mathrm{~mol}^{-1}$ for activation energy, $1.0 \times 10^{10} \mathrm{~s}^{-1}$ for the pre-exponential factor, 0.5 for the coefficient $c_{j}$ and 1 for the reaction order. 
The parameter $\lambda$ is set to 0.5 . The optimized kinetic parameters for the polyurethane pyrolysis are shown in table 1 . The final value of the objective function is $10.81 \%$. From the optimal coefficient $c_{j}$, we find that about 0.45 of the polyurethane is decomposed in the first stage while about 0.55 is decomposed during the second one. It is worth noting that as the sum of the $c_{j}$ coefficient has to be equal to 1 , the obtained values $c_{j}$ have been normalized to satisfy this condition. These results may be explained by the fact that each stage represents the decomposition of one of the organic resins from which the polyurethane is synthesized. From the results, it can be seen also that the polyurethane pyrolysis has a reaction order close to two in the 2 step and to 3 in the second one.

TABLE 1: Kinetic parameters of polyurethane pyrolysis obtained using the Least-Squares Evaluation of three experiments

\begin{tabular}{lcccccc}
\hline Reactions & $c_{j}$ & $c_{j}^{\text {norm }}$ & $Z_{j}\left(\mathrm{~s}^{-1}\right)$ & $E a_{j}\left(\mathrm{~kJ} \mathrm{~mol}^{-1}\right)$ & $n_{j}$ & Of $(\%)$ \\
\hline 1 & 0.454 & 0.450 & $2.45 \times 10^{4}$ & 59.8 & 1.905 & 10.81 \\
2 & 0.556 & 0.550 & $1.20 \times 10^{6}$ & 107.2 & 2.882 & \\
\hline
\end{tabular}

Examples of comparison between the calculated and experimental results of polyurethane pyrolysis at the slowest and fastest heating rates, 20 and $80{ }^{\circ} \mathrm{C} \mathrm{min}^{-1}$, are presented on the figure 2. The figures show that the model can globally follow the shape of the peak temperatures in the different stages of polyurethane decomposition. However, the two reactions model could not determine accurately the position of the peaks along the temperature axis and their height. Moreover, the figures indicate that the model did not reproduce the shoulders appearing on the first and second stages of the DTG curves. We note that a shoulder represent generally a peak temperature which overlap another neighboring peak temperature [47].

\subsection{Decomposition of polyurethane by four parallel reactions}

It is somewhat difficult to describe each step by one reaction. That is why we have supposed that each step occurs by two parallel independent reactions highly overlapping each other. Therefore, the polyurethane pyrolysis is supposed to be done by four parallel independent reactions. In order to determine the kinetic parameters of these reactions by least square method, we chose equal initial values of the kinetics parameters : $0.25,1.0 \times 10^{10} \mathrm{~s}^{-1}, 1 \times 10^{5} \mathrm{~kJ} \mathrm{~mol}^{-1}, 1$ for $c_{j}, Z_{j}$, $E a_{j}$ and $n_{j}$ respectively. We take $\lambda$ equal to 0.5 . The initial value of the objective function equals $103.47 \%$. The best value of the objective function obtained by the minimization process is about of $5.56 \%$. Table 2 shows the estimated kinetic parameters obtained from the pyrolysis of polyurethane. Figure 3 shows the curves of the conversion ratio and conversion rate obtained by TGA analysis and the used kinetic model at the slowest and fastest heating rates : 20 and $80{ }^{\circ} \mathrm{Cmin}^{-1}$. We can observe a good agreement between experimental and calculated result. We note that the optimal objective function decreased from $10.81 \%$ in the case of two reactions model to $5.56 \%$ for the four reactions model. The decrease of the objective function proves that the latter one fits better the experimental data. The use of four reactions model allow to describe successfully the shoulders appearing in the DTG curves for both slowest and fastest heating rates. Furthermore, the four reactions model determined more precisely the position of the peaks along the temperature axis. However, the fit still slightly inaccurate to describe the peak height especially for the fastest heating rate. 


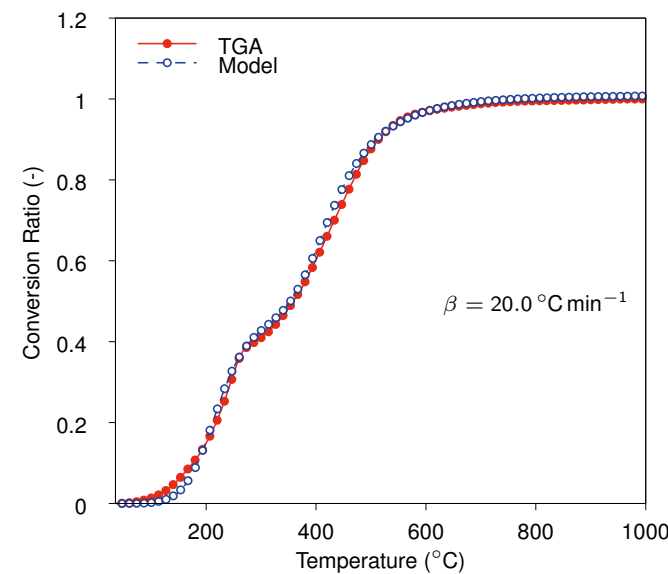

(a) TG curves

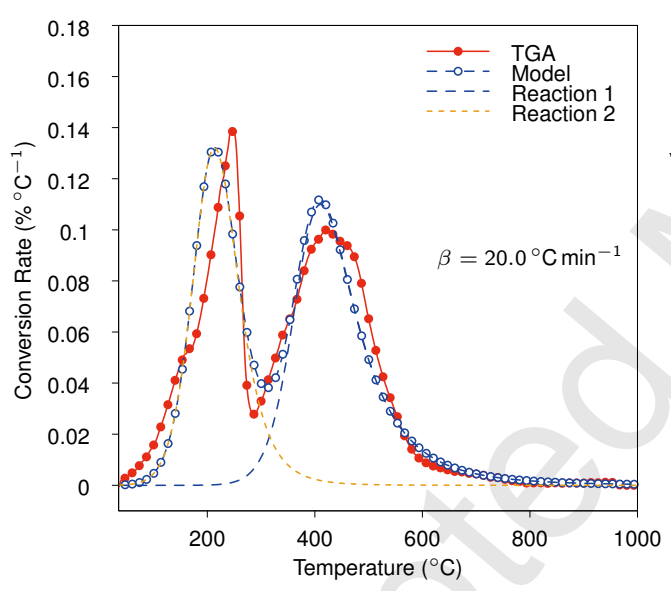

(c) DTG curves

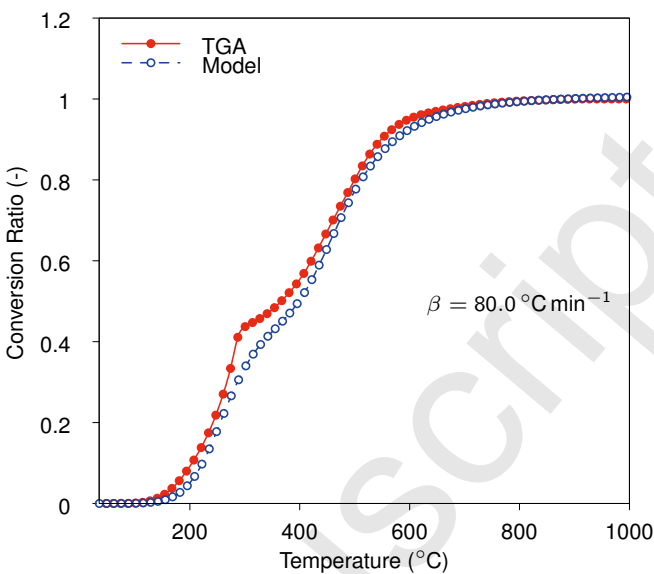

(b) TG curves

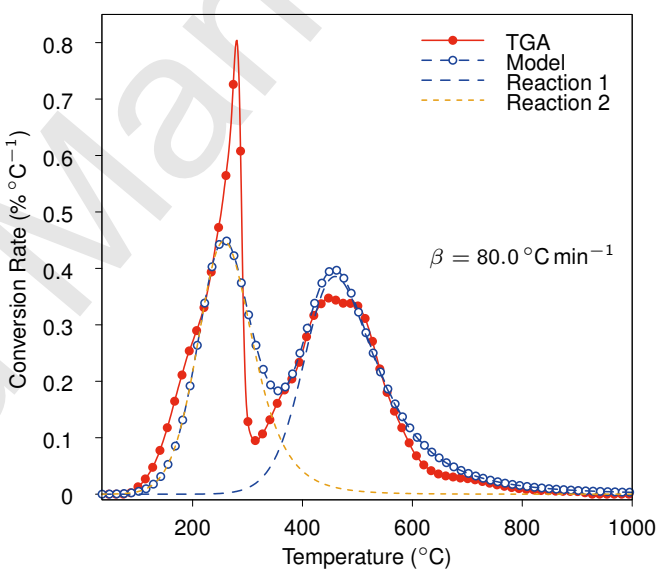

(d) DTG curves

FIGURE 2: Experimental and calculated pyrolysis TG and DTG curves at the slowest and fastest heating rates, 20 and $80^{\circ} \mathrm{C} \mathrm{min}^{-1}$, for 2-parallel independent reactions model

TABLE 2: Kinetic parameters of polyurethane pyrolysis obtained using the Least-Squares Evaluation of three experiments

\begin{tabular}{lcccccc}
\hline Reactions & $c_{j}$ & $c_{j}^{\text {norm }}$ & $Z_{j}\left(\mathrm{~s}^{-1}\right)$ & $E a_{j}\left(\mathrm{~kJ} \mathrm{~mol}^{-1}\right)$ & $n_{j}$ & Of $(\%)$ \\
\hline 1 & 0.334 & 0.331 & $9.95 \times 10^{4}$ & 59.650 & 4.455 & \\
2 & 0.160 & 0.159 & $1.50 \times 10^{10}$ & 118.12 & 0.857 & \\
3 & 0.235 & 0.233 & $3.187 \times 10^{7}$ & 117.09 & 2.336 & 5.57 \\
4 & 0.280 & 0.277 & $4.26 \times 10^{8}$ & 148.07 & 2.575 & \\
\hline
\end{tabular}




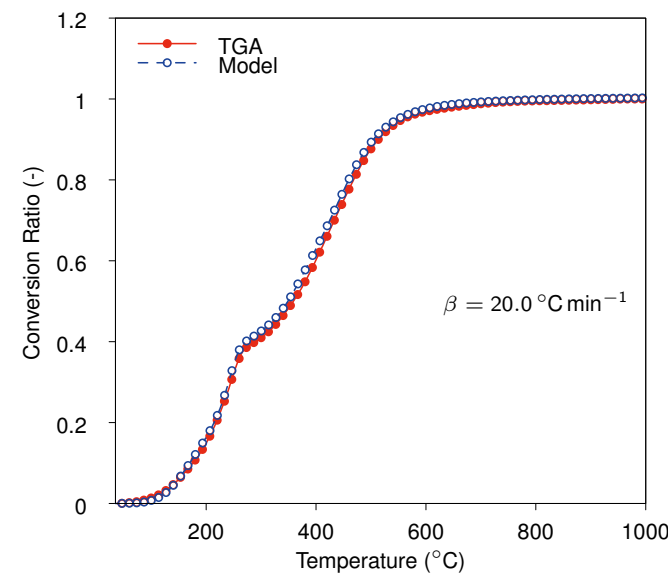

(a) TG curves

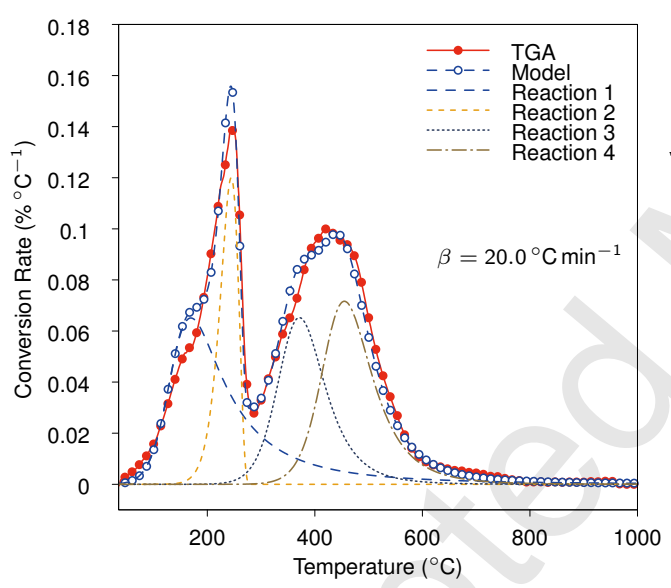

(c) DTG curves

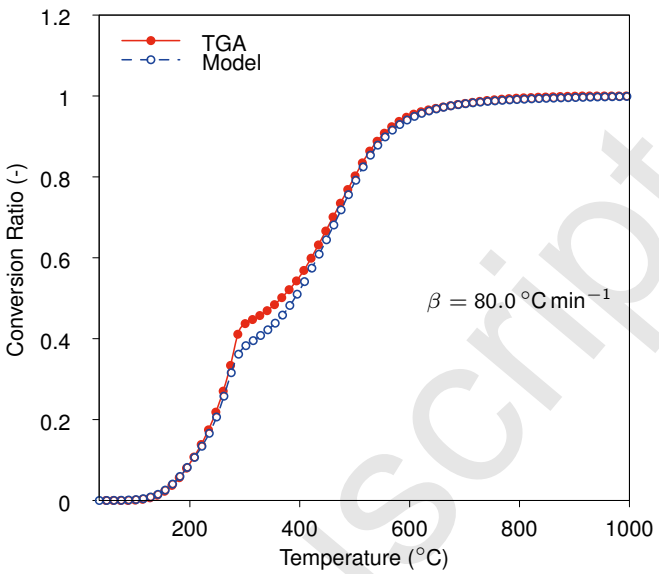

(b) TG curves

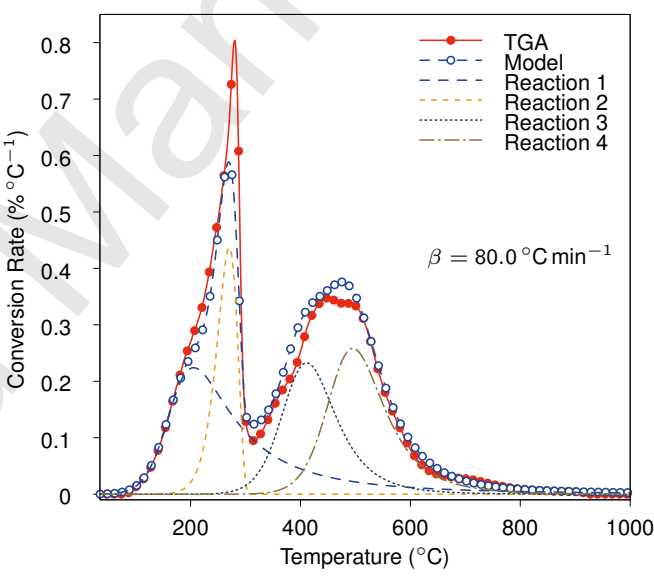

(d) DTG curves

FIGURE 3: Comparison between experimental and calculated data at the slowest and fastest heating rates, 20 and $80^{\circ} \mathrm{C} \mathrm{min}^{-1}$, for 4-parallel independent reactions model

\subsection{Effect of thermal-lag on the kinetic analysis}

In the above sections, we have taken the temperature of samples uniform and equal to the TGA furnace temperature. The latter one increases linearly as a function of time at the constant heating rate $\beta$ (cf. eq.(10)). In reality, there is a thermal lag (deviation) between the true sample and furnace temperatures. Indeed, they could be equal only on the surface of the sample. Many papers have investigated thermal lag occurring during TGA analysis [52-56]. These papers reported that the thermal lag could be affected by many factors such as heating rate, initial size/mass of the sample, thermal effect of the reactions (heat generation/absorption by exothermic/endothermic reactions), the composition and the thermo-physical properties of the sample and the carrier gas of TGA, etc [52-55].

The temperature of the polyurethane samples was measured during the TGA measurements 
conducted in the current study. Figure 4 shows that there is an important deviation between the measured and furnace temperatures (henceforth noted $T_{m}$ and $T_{f}$ respectively) for the three chosen heating rates 20,60 and $80{ }^{\circ} \mathrm{C} \mathrm{min}^{-1}$. The maximum thermal lags $(T m-T f)$ are equal to $67.99,86.81$ and $87.70^{\circ} \mathrm{C}$ for these three heating rates respectively. The variation of the sample temperature as a function of time can be re-described by a linear relation with new heating rates which are $21.28,65.46$ and $88.15^{\circ} \mathrm{C} \mathrm{min}^{-1}$. One can explain these higher thermal lags essentially by three factors which are the heating rates, initial mass of samples and the self-heating of the samples. Indeed as explained by many studies [52, 55], the thermal lag can dramatically increase with heating rate. Moreover, the use of an important initial sample mass can lead to the creation of temperature gradient and therefore to the increasing of thermal-lag (particularly at higher heating rates). It was recommended that the heating rate and the initial mass samples should be less than $10^{\circ} \mathrm{C} \mathrm{min}^{-1}$ and $10 \mathrm{mg}$ respectively in order to minimize the thermal-lag [54]. The violation of these recommendations in the measurements conducted in the current study (the initial mass of the samples are $16.7,16.0$ and $16.4 \mathrm{mg}$ and the heating rates are 20,60 and $80{ }^{\circ} \mathrm{C} \mathrm{min}^{-1}$ respectively) could explain the important thermal lag values occurring during TGA analyses. The third factor which can be noted from the positive deviation between the sample and the furnace temperatures is the self-heating. Indeed, as the temperature of the sample increases faster than that of the furnace, one can conclude that there is a heat generation occurring during polyurethane pyrolysis reaction (i.e. exothermic reaction). The self-heating of the sample can lead to a gradient temperature inside the sample (especially with higher initial mass) [54, 55]. To minimize the effect of the self-heating, one can use lower initial sample mass [55].

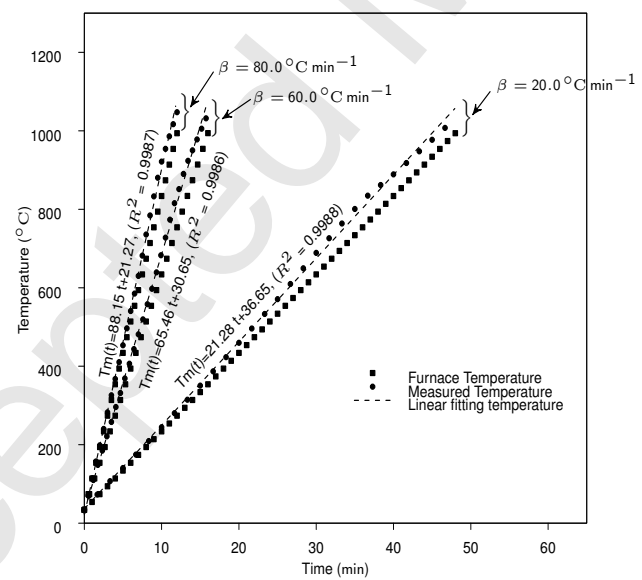

FIGURE 4: Variation of furnace and measured temperatures with respect to time at various heating rates : 20, 60 and $80{ }^{\circ} \mathrm{C} \mathrm{min}^{-1}$

In order to illustrate the effect of the thermal lag on the kinetic analysis of polyurethane pyrolysis, we will recalculate the kinetic parameters of the two reactions model using the sample temperature obtained at the three heating rates 20,60 and $80{ }^{\circ} \mathrm{C} \mathrm{min}^{-1}$. Even though we can use the new heating rates obtained by the linear regression of the sample temperature $(67.99,86.81$ and $87.70{ }^{\circ} \mathrm{C}$ ) in the new kinetic analysis of polyurethane pyrolysis, we will use the raw values of the sample temperature measured by the thermocouple during the TGA experiments. The same initial values of the kinetic parameters used in the previous kinetic analysis with two reactions 
model were used in the current one. The new optimized kinetic parameters were obtained for a objective function of $10.84 \%$. There parameters are shown in table 3 . The new results of kinetic analysis of polyurethane pyrolysis illustrate that taking into account the thermal lag leads to different kinetic parameters. The new activation energies of the first and second reactions are greater than that obtained for the furnace temperature $\left(60.5\right.$ and $110.6 \mathrm{~kJ} \mathrm{~mol}^{-1}$ instead of 59.8 and $107.2 \mathrm{~kJ} \mathrm{~mol}^{-1}$ respectively). The exponential factor of the first reaction was decreased from $2.24 \times 10^{4}$ to $2.45 \times 10^{4} \mathrm{~s}^{-1}$, however that of second reaction was increased from $1.20 \times 10^{6}$ to $1.22 \times 10^{6} \mathrm{~s}^{-1}$. The orders of first and second reactions were increased to become 2.038 and 3.022 instead of 1.905 and 2.882 respectively. One can also note that the objective function Of of the current kinetic analysis (has a value of $10.84 \%$ ) is just slightly higher than the one obtained in the case of use the furnace temperature (equals to $10.81 \%$ ).

The recalculation of the kinetic parameters using the sample temperature shows that the accuracy of the estimated parameters was severely affected by the thermal lag. In order to improve the accuracy of the kinetic analysis, new TGA experiments with lower heating rates and initial mass of samples should be done. Furthermore, the development of a more detailed heat transfer model within the sample will allow a more accurate kinetic analysis of polyurethane pyrolysis.

TABLE 3: Kinetic parameters of polyurethane pyrolysis calculated using the sample temperature

\begin{tabular}{lcccccc}
\hline Reactions & $c_{j}$ & $c_{j}^{\text {norm }}$ & $Z_{j}\left(\mathrm{~s}^{-1}\right)$ & $E a_{j}\left(\mathrm{~kJ} \mathrm{~mol}^{-1}\right)$ & $n_{j}$ & Of $(\%)$ \\
\hline 1 & 0.463 & 0.458 & $2.24 \times 10^{4}$ & 60.5 & 2.038 & 10.84 \\
2 & 0.547 & 0.542 & $1.22 \times 10^{6}$ & 110.6 & 3.022 & \\
\hline
\end{tabular}

\subsection{Estimation of activation energy by Kissinger's and Friedman's methods}

A comparison was conducted between the kinetic parameters estimated by the non-linear and linear fitting methods. The values of activation energy of each step was determined by two linear methods, namely Kissinger and Friedman methods. Table 4 presents the energy of activation of polyurethane decomposition calculated by the different methods.

To determine the activation energy of each reaction by Kissinger method, $T_{\max }^{2}$ is plotted as a function of $\frac{-1}{T_{\max }}$ for the peak of each step at different heating rates. $T_{\max }$ is the temperature corresponding to the maximum rate of decomposition. As explained above, the resulting plot is a straight line whose slope is $\frac{E a}{R}$. The estimated activation energy for the first and second steps are equal to 66.60 and $210.50 \mathrm{~kJ} \mathrm{~mol}^{-1}$, respectively. The value of the square of correlation coefficient $\left(r^{2}\right)$ is equal to 0.9667 for the first step and 0.8939 for the second one, which can indicate that the experimental data are well fitted by linear plot for the two steps.

The determination of activation energy by the Friedman method was carried out for two conversion degrees of 0.15 and 0.85 which are chosen to be in the first and second stage respectively. Plotting of $\ln \left(\beta \frac{d \alpha_{M}}{d T}\right)$ as a function of $\frac{1}{T}$ for each conversion degree leads to the estimated values of activation energy of 111.5 and $202.9 \mathrm{~kJ} \mathrm{~mol}^{-1}$ for the first and second stage respectively. The square of the correlation coefficient of Friedman plot of the first and second stage are equals to 0.9999 and 0.9909 respectively.

The results show that the values of the activation energy obtained by the different methods are globally quite different. The values of the activation energies obtained by non-linear fitting are generally lower than those obtained by Kissinger and Friedman methods. However, the value of activation energy obtained for the first stage using the non-linear fitting method $\left(59.80 \mathrm{~kJ} \mathrm{~mol}^{-1}\right)$ 
TABLE 4: Activation energies of polyurethane decomposition estimated by the different methods

\begin{tabular}{lcc}
\hline Methods & $E a_{1}\left(\mathrm{~kJ} \mathrm{~mol}^{-1}\right)$ & $E a_{2}\left(\mathrm{~kJ} \mathrm{~mol}^{-1}\right)$ \\
\hline Non-linear & 59.80 & 107.2 \\
Kissinger & 66.60 & 210.5 \\
Friedman & 115.5 & 202.9 \\
\hline
\end{tabular}

is close to that obtained by Kissinger method $\left(66.60 \mathrm{~kJ} \mathrm{~mol}^{-1}\right)$. For the second stage, the values obtained by the Kissinger and Friedman methods are quite similar, 210.5 and $202.9 \mathrm{~kJ} \mathrm{~mol}^{-1}$ res- $^{-}$ pectively. The difference between the results obtained by the different methods may be attributed to the dissimilar mathematical treatment in each method.

\subsection{Comparison of current results with published ones}

Many studies have investigated the pyrolysis of polyurethane. A comparison between of the estimated kinetic parameters published in the literature and those obtained by the current study is given in table 5. Different types of polyurethane have been analyzed in this studies. Font et al [12] studied the pyrolysis of commercial polyurethane obtained by the reaction bewteen the polyadipate of 1,4-butanediol or 1,6-hexanediol with diphenylmethane p,p\%-diisocyanate. Rein et al [57] studied the flexible polyurethane foam. Prasad et al [58] studied polyurethane foam formed out of a reaction between toluene diisocynate (TDI)and a polyol. Pau et al [59] studied polyurethane foams made from the reaction of mainly toluene diisocyanate and polyalkoxy polyether polyol.

TABLE 5: Comparison between the kinetic parameters of polyurethane pyrolysis obtained in this work with other published results

\begin{tabular}{llll}
\hline & $E a_{j}\left(\mathrm{~kJ} \mathrm{~mol}^{-1}\right)$ & $Z_{j}\left(\mathrm{~s}^{-1}\right)$ & $n_{j}$ \\
\hline \multirow{2}{*}{ Font et al [12] } & 133.6 & $2.55 \times 10^{12}$ & 0.951 \\
& 190.4 & $9.76 \times 10^{15}$ & 0.668 \\
\cline { 2 - 4 } Rein et al [57] & 124.0 & $1.58 \times 10^{8}$ & 1.140 \\
& 148.0 & $2.00 \times 10^{11}$ & 0.210 \\
\cline { 2 - 4 } Prasad et al [58] & 135.0 & $1.69 \times 10^{8}$ & 1.000 \\
& 175.0 & $8.75 \times 10^{9}$ & 1.160 \\
\cline { 2 - 4 } Pau et al [59] & 179.0 & $3.61 \times 10^{14}$ & 9.510 \\
& 231.0 & $4.72 \times 10^{16}$ & 1.230 \\
\cline { 2 - 4 } Present Work & 59.8 & $2.45 \times 10^{4}$ & 1.905 \\
& 107.2 & $1.20 \times 10^{6}$ & 2.882 \\
\hline
\end{tabular}

The presented results show that the obtained kinetics parameters (activation energies and preexponential factors) in the present work are the lowest compared to the the published ones. The difference between the kinetic parameters estimated in this study and those calculated by other workers may probably be attributed the fact that types of studied polyurethane are different. 
The kinetic models used to describe polyurethane pyrolysis may also influence the obtained values kinetic parameters. Other factors include the experimental conditions of thermogravimetric analysis and the calculation procedure used to determine the kinetic parameters can cause the difference between the values of the estimated parameters.

\section{Conclusion}

A kinetic analysis for the polyurethane pyrolysis was conducted in this paper. Thermal analysis of the polyurethane was carried out with the thermogravimetry technique which allows a non-isothermal determination of conversion ratio and conversion rate curves as a function of heating rate. Different experiments for polyurethane pyrolysis were conducted at different heating rates. The experimental results showed that the polyurethane pyrolysis is mainly completed in two steps, the first one takes place between 100 and $300{ }^{\circ} \mathrm{C}$, and the second occurs between 300 and extends to $800^{\circ} \mathrm{C}$.

A kinetic model has been presented to describe solid matter pyrolysis during the TGA analysis. This model is based on the parallel independent reactions models. In order to determine the kinetic parameters of the different reactions of polyurethane pyrolysis, a nonlinear least-square procedure has been used. The proposed model has been employed to describe the polyurethane pyrolysis using two and four reactions. The results shows that the use of four reactions model allowed to described more accurately the experimental data, particularly to reproduce the highly overlapped reactions (shoulders). A comparison of the kinetic parameters calculated using the sample and the furnace temperatures showed that thermal-lag can affect considerably the kinetic analysis. In order to improve the reliability of the kinetic analysis, one should minimize the deviation between the sample and furnace temperature (thermal-lag). The kinetics parameters of polyurethane pyrolysis estimated in the paper would be used later in CFD codes to simulate gas emission occurring during casting process.

\section{Acknowledgement}

This study is fully-funded by Montupet SA. The authors would like to express their deep acknowledgment to Montupet. We thank INERIS (Institut National de 1'Environnement Industriel et des RISques) for their technical support in TGA experiments. We are grateful to Dr. Vahid Ebrahimian and M. Aghiles Garah for their help in this work. Finally, we thank the reviewers whose thoughtful guidance helped to improve the manuscript. 
[1] M. Divandari, J. Campbell, Mechanisms of bubble damage in castings, in : A. F. Society (Ed.), 1st International Conference on Gating, Filling and Feeding of Aluminum Castings : Oct. 11 - 13, 1999, Opryland Hotel, Nashville, TN, 1999, pp. 49-63.

[2] J. Campbell, Complete Casting Handbook : Metal Casting Processes, Techniques and Design, 1st Edition, ELSEVIER, 2011.

[3] J. H. Flynn, L. A. Wall, General treatment of the thermogravimetry of polymers, J Res Nat Bur Stand 70 (6) (1966) 487-523.

[4] R. Font, A. Fullana, J. Caballero, J. Candela, A. García, Pyrolysis study of polyurethane, Journal of Analytical and Applied Pyrolysis 58-59 (0) (2001b) $63-77$.

[5] C. A. Lytle, W. Bertsch, M. D. McKinley, Determination of thermal decomposition products from a phenolic urethane resin by pyrolysis-gas chromatography-mass spectrometry, Journal of High Resolution Chromatography 21 (2) (1998) 128-132.

[6] R. S. Dungan, J. B. Reeves III, Pyrolysis of foundry sand resins : A determination of organic products by mass spectrometry, Journal of Environmental Science and Health, Part A 40 (8) (2005) 1557-1567.

[7] Y. Wang, F. S. Cannon, M. Salama, J. Goudzwaard, J. C. Furness, Characterization of hydrocarbon emissions from green sand foundry core binders by analytical pyrolysis, Environmental Science \& Technology 41 (22) (2007) $7922-7927$.

[8] G. Jomaa, Étude des dégagements gazeux survenant pendant la coulée de pièces d'aluminium, Ph.D. thesis, MINES-ParisTech, France (2014).

[9] J. Caballero, R. Font, M. Esperanza, Kinetics of the thermal decomposition of tannery waste, Journal of Analytical and Applied Pyrolysis 47 (2) (1998) 165 - 181

[10] J. Park, S. Oh, H. Lee, H. Kim, K. Yoo, Kinetic analysis of thermal decomposition of polymer using a dynamic model, Korean Journal of Chemical Engineering 17 (5) (2000) 489-496.

[11] J. Conesa, A. Marcilla, J. Caballero, R. Font, Comments on the validity and utility of the different methods for kinetic analysis of thermogravimetric data, Journal of Analytical and Applied Pyrolysis 58-59 (0) (2001) 617 633.

[12] R. Font, I. Martín-Gullń, M. Esperanza, A. Fullana, Kinetic law for solids decomposition. application to thermal degradation of heterogeneous materials, Journal of Analytical and Applied Pyrolysis 58-59 (0) (2001a) 703 - 731.

[13] R. Font, A. Marcilla, A. García, J. Caballero, J. Conesa, Comparison between the pyrolysis products obtained from different organic wastes at high temperatures, Journal of Analytical and Applied Pyrolysis 32 (0) (1995) 41 - 49.

[14] G. Várhegyi, M. J. A. Jr., E. Jakab, P. Szabó, Kinetic modeling of biomass pyrolysis, Journal of Analytical and Applied Pyrolysis 42 (1) (1997) $73-87$.

[15] R. Rodríguez, D. Gauthier, S. Udaquiola, G. Mazza, O. Martinez, G. Flamant, R. J. LeBlanc, P. J. Laughton, R. Tyagi, Kinetic models for pyrolysis and combustion of sewage sludge, in : Conference, Proceedings on Moving Forward Wastewater Biosolids Sustainability : Technical, Managerial, and Public Synergy, GMSC, 2007, pp. 801809.

[16] S. Hu, A. Jess, M. Xu, Kinetic study of chinese biomass slow pyrolysis : Comparison of different kinetic models, Fuel 86 (17-18) (2007) $2778-2788$.

[17] Z. Li, W. Zhao, B. Meng, C. Liu, Q. Zhu, G. Zhao, Kinetic study of corn straw pyrolysis : Comparison of two different three-pseudocomponent models, Bioresource Technology 99 (16) (2008) 7616 - 7622.

[18] K. Miura, T. Maki, A simple method for estimating $\mathrm{f}(\mathrm{e})$ and $\mathrm{k} 0(\mathrm{e})$ in the distributed activation energy model, Energy \& Fuels 12 (5) (1998) 864-869.

[19] S. Scott, J. Dennis, J. Davidson, A. Hayhurst, An algorithm for determining the kinetics of devolatilisation of complex solid fuels from thermogravimetric experiments, Chemical Engineering Science 61 (8) (2006) 2339 2348 .

[20] T. Sonobe, N. Worasuwannarak, Kinetic analyses of biomass pyrolysis using the distributed activation energy model, Fuel 87 (3) (2008) $414-421$.

[21] J. Cai, R. Liu, New distributed activation energy model : Numerical solution and application to pyrolysis kinetics of some types of biomass, Bioresource Technology 99 (8) (2008) 2795 - 2799.

[22] G. Várhegyi, C. Honggang, G. Sandra, Thermal decomposition of wheat, oat, barley, and brassica carinata straws. a kinetic study, Energy \& Fuels 23 (2) (2009b) 646-652.

[23] S. Vyazovkin, C. A. Wight, Isothermal and non-isothermal kinetics of thermally stimulated reactions of solids, International Reviews in Physical Chemistry 17 (3) (1998) 407-433.

[24] R. K. Agrawal, Analysis of non-isothermal reaction kinetics : Part 1. simple reactions, Thermochimica Acta 203 (0) (1992) $93-110$.

[25] C. Popescu, Integral method to analyze the kinetics of heterogeneous reactions under non-isothermal conditions a variant on the ozawa-flynn-wall method, Thermochimica Acta 285 (2) (1996) $309-323$.

[26] A. K. Galwey, M. E. Brown, Chapter 3 kinetic background to thermal analysis and calorimetry, in : M. E. Brown (Ed.), Principles and Practic, Vol. 1 of Handbook of Thermal Analysis and Calorimetry, Elsevier Science B.V., 
1998 , pp. $147-224$

[27] J. Zhang, L. Ge, X. Zhang, Y. Dai, H. Chen, L. Mo, Thermal decomposition kinetics of the Zn(II) complex with norfloxacin in static air atmosphere, Journal of Thermal Analysis and Calorimetry 58 (2) (1999) 269-278.

[28] J. Órfão, F. Martins, Kinetic analysis of thermogravimetric data obtained under linear temperature programming —a method based on calculations of the temperature integral by interpolation, Thermochimica Acta 390 (1-2) (2002) $195-211$.

[29] L. Vlaev, I. Markovska, L. Lyubchev, Non-isothermal kinetics of pyrolysis of rice husk, Thermochimica Acta $406(1-2)(2003) 1-7$.

[30] K. Chrissafis, Kinetics of thermal degradation of polymers, Journal of Thermal Analysis and Calorimetry 95 (1) (2009) 273-283

[31] A. Khawam, Application of solid-state kinetics to desolvation reactions, Ph.D. thesis (2007).

[32] F. Yao, Q. Wu, Y. Lei, W. Guo, Y. Xu, Thermal decomposition kinetics of natural fibers : Activation energy with dynamic thermogravimetric analysis, Polymer Degradation and Stability 93 (1) (2008) 90 - 98.

[33] N. Sbirrazzuoli, L. Vincent, A. Mija, N. Guigo, Integral, differential and advanced isoconversional methods : Complex mechanisms and isothermal predicted conversion-time curves, Chemometrics and Intelligent Laboratory Systems 96 (2) (2009) $219-226$.

[34] K. Slopiecka, P. Bartocci, F. Fantozzi, Thermogravimetric analysis and kinetic study of poplar wood pyrolysis, Applied Energy 97 (0) (2012) 491 - 497.

[35] H. L. Friedman, Kinetics of thermal degradation of char-forming plastics from thermogravimetry. application to a phenolic plastic, Journal of Polymer Science Part C : Polymer Symposia 6 (1) (1964) 183-195.

[36] H. E. Kissinger, Reaction kinetics in differential thermal analysis, Analytical Chemistry 29 (11) (1957) 1702-1706.

[37] H. Anderson, A. Kemmler, R. Strey, Comparison of different non-linear evaluation methods in thermal analysis, Thermochimica Acta 271 (0) (1996) 23 - 29.

[38] H. Anderson, R. Strey, A. Kemmler, D. Haberland, Effective search of starting values for kinetic parameters estimation, Journal of thermal analysis 49 (3) (1997) 1565-1569.

[39] J. Opfermann, Kinetic analysis using multivariate non-linear regression. i. basic concepts, Journal of Thermal Analysis and Calorimetry 60 (2) (2000) 641-658.

[40] G. Várhegyi, L. Pöppl, I. Földvári, Kinetics of the oxidation of bismuth tellurite, bi2teo5 : Empirical model and least squares evaluation strategies to obtain reliable kinetic information, Thermochimica Acta 399 (1-2) (2003) 225 $-239$

[41] C. Reverte, J.-L. Dirion, M. Cabassud, Kinetic model identification and parameters estimation from \{TGA $\}$ experiments, Journal of Analytical and Applied Pyrolysis 79 (1-2) (2007) 297 - 305.

[42] C. Zhang, X. Jiang, L. Wei, H. Wang, Research on pyrolysis characteristics and kinetics of super fine and conventional pulverized coal, Energy Conversion and Management 48 (3) (2007) 797 - 802.

[43] J. A. Conesa, A. Marcilla, R. Font, J. Caballero, Thermogravimetric studies on the thermal decomposition of polyethylene, Journal of Analytical and Applied Pyrolysis 36 (1) (1996) 1 - 15.

[44] G. Várhegyi, P. Szabó, M. J. Antal, Kinetics of charcoal devolatilization, Energy \& Fuels 16 (3) (2002) 724-731.

[45] J. Caballero, J. Conesa, I. Martín-Gullón, R. Font, Kinetic study of the pyrolysis of neoprene, Journal of Analytical and Applied Pyrolysis 74 (1-2) (2005) $231-237$.

[46] J. Yan, H. Zhu, X. Jiang, Y. Chi, K. Cen, Analysis of volatile species kinetics during typical medical waste materials pyrolysis using a distributed activation energy model, Journal of Hazardous Materials 162 (2-3) (2009) 646-651.

[47] M. G. Grønli, G. Várhegyi, C. Di Blasi, Thermogravimetric analysis and devolatilization kinetics of wood, Industrial \& Engineering Chemistry Research 41 (17) (2002) 4201-4208.

[48] D. Vamvuka, E. Kastanaki, M. Lasithiotakis, Devolatilization and combustion kinetics of low-rank coal blends from dynamic measurements, Industrial \& Engineering Chemistry Research 42 (20) (2003) $4732-4740$.

[49] G. Várhegyi, Z. Sebestyén, Z. Czégény, F. Lezsovits, S. Könczöl, Combustion kinetics of biomass materials in the kinetic regime, Energy \& Fuels 26 (2) (2012) 1323-1335.

[50] R. Hooke, T. A. Jeeves, " direct search" solution of numerical and statistical problems, J. ACM 8 (2) (1961) 212 229.

[51] V. Torczon, On the convergence of pattern search algorithms, SIAM Journal on Optimization 7 (1) (1997) 1-25.

[52] M. J. Antal, G. o. Várhegyi, E. Jakab, Cellulose pyrolysis kinetics : revisited, Industrial \& engineering chemistry research 37 (4) (1998) 1267-1275.

[53] Y.-C. Lin, J. Cho, G. A. Tompsett, P. R. Westmoreland, G. W. Huber, Kinetics and mechanism of cellulose pyrolysis, The Journal of Physical Chemistry C 113 (46) (2009) 20097-20107.

[54] R. E. Lyon, N. Safronava, J. Senese, S. I. Stoliarov, Thermokinetic model of sample response in nonisothermal analysis, Thermochimica Acta 545 (0) (2012) 82 - 89.

[55] S. Vyazovkin, K. Chrissafis, M. L. D. Lorenzo, N. Koga, M. Pijolat, B. Roduit, N. Sbirrazzuoli, J. J. Suñol, \{ICTAC \} kinetics committee recommendations for collecting experimental thermal analysis data for kinetic computations, Thermochimica Acta 590 (0) (2014) 1 - 23. 
[56] A. K. Burnham, Obtaining reliable phenomenological chemical kinetic models for real-world applications, Thermochimica Acta 597 (0) (2014) $35-40$.

[57] G. Rein, C. Lautenberger, A. C. Fernandez-Pello, J. L. Torero, D. L. Urban, Application of genetic algorithms and thermogravimetry to determine the kinetics of polyurethane foam in smoldering combustion, Combustion and Flame 146 (1-2) (2006) 95 - 108

[58] K. Prasad, R. Kramer, N. Marsh, M. Nyden, T. Ohlemiller, M. Zammarano, Numerical simulation of fire spread on polyurethane foam slabs, in : Proceedings of the 11th international conference on fire and materials. Interscience Communications, London, 2009, pp. 697-708.

[59] D. S. Pau, C. M. Fleischmann, M. J. Spearpoint, K. Y. Li, Determination of kinetic properties of polyurethane foam decomposition for pyrolysis modelling, Journal of Fire Sciences 31 (4) (2013) 356-384. 